\title{
ANTROPOLOGÍA DE UNA APORÍA URBANA: ENTRE SER CIUDADES MEDIAS E IMAGINAR LA METRÓPOLIS
}

\author{
Julieta Gaztañaga ${ }^{1}$
}

\section{Introducción}

Miguel de Cervantes Saavedra construyó buena parte de "El Ingenioso Hidalgo Don Quijote de la Mancha" desarrollando el problema de la política, la autoridad y el gobierno. En el capítulo LI de la segunda parte, el labrador devenido escudero es nombrado gobernador de la Ínsula Barataria y en el contexto de esta farsa organizada por los Duques para el divertimento cortesano, recibe la consulta de un forastero:

\begin{abstract}
Señor, un caudaloso río dividía dos términos de un mismo señorío (y esté vuestra merced atento, porque el caso es de importancia y algo dificultoso); digo pues, que sobre este río estaba una puente, y al cabo della, una horca y una como casa de audiencia, en la cual de ordinario había cuatro jueces que juzgaban la ley que puso el dueño del río, de la puente y del señorío, que era en esta forma: si alguno pasare por esta puente de una parte a otra, ha de jurar primero adónde y a qué va; y si jurare verdad, déjenle pasar; y si dijere mentira, muera, por ello ahorcado en la horca que allí se muestra, sin remisión alguna. Sabida esta ley y la rigurosa condición della, pasaban muchos, y luego en lo que juraban se echaba de ver que decían verdad, y los jueces los dejaban pasar libremente. Sucedió, pues, que tomando juramento a un hombre, juró y dijo que para el juramento que hacía, que iba a morir en aquella horca que allí estaba, y no a otra cosa. Repararon los jueces en el juramento, y dijeron: Si a este hombre le dejamos pasar libremente, mintió en su juramento, y conforme a la ley debe morir; y si le ahorcamos, él juró que iba a morir en aquella horca, y habiendo jurado verdad, por la misma ley debe ser libre. Pídase a vuestra merced, señor gobernador, ¿qué harán los jueces del tal hombre; que aún hasta agora están dudosos y suspensos? (Cervantes Saavedra, 1910: 817).
\end{abstract}

Tras un breve intercambio acerca del caso (la verdad salva al hombre tanto como la mentira le condena), Sancho decide suspender la lógica impersonal y realiza un acto de gobierno inspirado en el precepto que recibiera de don Quijote la noche anterior a convertirse en gobernador. Este le había aconsejado que cuando la justicia estuviera en duda se acogiese a la misericordia. Responde entonces: que le dejen pasar por el puente.

En este ejemplo de fines del siglo XVI la capacidad de atravesar un puente depende de un acto de justicia arbitrario que encarna una voluntad política. En la actualidad la capacidad de transitar por un puente, una carretera o una autopista representa el poder de la presencia del Estado y también revela la naturaleza contingente pero potencialmente transformadora de sus proyectos de dominación. La obra pública

\footnotetext{
${ }^{1}$ Universidad de Buenos Aires, Argentina.
} 
constituye una arena conflictiva donde se dirimen lo arbitrario y lo inevitable de la neutralidad tecnológica y el relevamiento de necesidades socialmente problematizadas. Pone a prueba la capacidad de respuesta y de acción de una miríada de instituciones públicas y privadas, y siempre implica representaciones políticas del espacio y una economía política de su materialidad. Las fronteras interiores y los márgenes del Estado (Das y Poole, 2008) son fijados, irónicamente, a través de diferentes movimientos en sus formas y recorridos (tránsito, inversión, encuentro, escape, pasaje, defensa, trinchera, puesto de control, entre otros). Como habitantes de ciudades podemos reconocer estos procesos en experiencias propias: el paso a nivel donde se reúnen los adolescentes para gritar cuando pasa el tren, el banco de plaza de una declaración de amor removido por ampliación de la vereda, o el barrio de los abuelos relocalizado por una autopista, todos pertenecen al "espacio conceptualizado" de los científicos, planificadores urbanos, técnicos e ingenieros sociales (Lefebvre, 1991: 38).

La importancia que en los últimos años se ha dado al carácter vivido de estas infraestructuras urbanas se puede trazar en casi todas las disciplinas sociales. Por ejemplo, los trabajos sobre transporte y territorio han sufrido en los últimos años un cambio de énfasis desde reconstruir las historias de los productores de infraestructuras (siendo los ferrocarriles el ejemplo paradigmático) hasta conceptualizar sistemas y redes de transporte que, desde el auge automotor hasta la actualidad, permiten entablar diálogos con temáticas como segregación espacial, gentrificación y diferentes formas del derecho a la ciudad. También se han renovado las discusiones clásicas sobre lo urbano ¿Ha sido el tráfico aquello que históricamente produjo el surgimiento de las ciudades? ¿La ciudad es una unidad socioeconómica definida o lo urbano es un espacio sui generis que resulta de flujos que en cierto punto se encuentran? ¿La forma espacial determina las condiciones sociales, inclusive las identidades sociales, o es la estructura socio-económica la que determina la forma urbana y la distribución espacial? La vigencia de estas preguntas es la de la exposición objetivada de las tensiones ideológicas y analíticas que siguen recorriendo las políticas de desarrollo globales, las luchas de colectivos y personas por su dignidad, y la experiencia dramáticos del avance de la acumulación por desposesión (Harvey, 2005). 
Entre las renovaciones más recientes del tema talla un importante núcleo de indagación afiliado al mobility turn (Urry, 2007: 3-16). No solo dieron por tierra con una idea de movilidad como traslado de un punto a otro sino que mostraron que aún las formas más triviales de viaje urbano representan una experiencia completa de habitar el espacio (Agnew, 2005; Jensen, 2013; Lois, 2010; Salazar, 2016; Singh, 2013). Con ello, han discutido también las concepciones duales y negativas de lo urbano propias de la geografía y la sociología clásicas incorporando, en cambio, al "espacio como dimensión de multiplicidad" (Massey, 1995: 55). Estos trabajos han enriquecido el estudio de la política de las movilidades como experiencias personales, normativas y de regímenes institucionales, por cuanto plantean que la capacidad de ser móvil (motility) no es un atributo de personas o cosas, sino parte de un proceso dinámico de tecnologías, prácticas socio-espaciales y representaciones, inseparable de los modos en que los actores acceden y se apropian de aquella (Kaufmann et al., 2004). Sin embargo, al presentar a las tecnologías de transporte como mediación entre lo material y lo cultural según una concepción generalizada de las relaciones de poder, los proyectos de infraestructura y de las prácticas socioespaciales concomitantes acaban entramados de facto o laxamente analizados dentro de los procesos de destrucción creativa de infraestructura material (Harvey, 2005), víctimas de aquello que Pierre Bourdieu (1998) llamó la utopía de la explotación ilimitada, una suerte de fetichismo de la infraestructura como un fin en sí mismo (Dalakoglou, 2016: 825).

Buena parte de las críticas mencionadas proviene de la antropología, la cual tiene su propio capítulo sobre el tema respecto de la movilidad como un marco analítico para reflexionar acerca de las sociedades humanas (Salazar, 2010) y la noción de alteridad como organizador cognoscitivo del viaje y el encuentro (Krotz, 2007). No obstante, es posible identificar al menos tres tipos de esfuerzos en este gran arco temático. Desde los pioneros estudios sobre la relación entre ideas e instituciones del paradigma evolucionista hasta los estudios de la "difusión" de la cultura que trazaban en Egipto el origen de la civilización, el tema de la movilidad y el emplazamiento poblacional ha sufrido todo tipo de transformaciones.

Movilidad e infraestructura han sido temas claves de la crítica sociocultural del capitalismo avanzado en diferentes trabajos ocupados en estudiar los movimientos de bienes y personas, el papel activo de actores y procesos locales en la constitución del sistema económico mundial (Mintz, 1985; Wolf, 1993), y el rol de las infraestructuras 
para garantizar sistemas de poder (Harris, 1968; Godelier et al., 1978; Ribeiro 1991). Estos enfoques, empero, han sido cuestionados por presentar una comprensión "antisocial" de los sistemas tecnológicos (Dalakoglou, 2016: 827), porque, de manera similar a la geografía crítica del neoliberalismo, no llegarían a recabar en la intimidad del poder en la vida humana en los contextos locales y en las relaciones que la gente construye con los Estados y otras estructuras de poder (Elyachar, 2012). No obstante, sus contribuciones han sido fundamentales para desnaturalizar el discurso occidental moderno del desarrollo como progreso y para ver a las grandes obras como factores de producción de desigualdad, exclusión, e inmovilidad (Green y Laviolette, 2017; Salazar y Jayaram, 2016; Turner, 2007; Tsing, 2005).

Un segundo conjunto de trabajos ha abordado estas problemáticas a partir de esfuerzos por desentrañar las fuerzas de la globalización. Los pioneros análisis en términos de flujos, fragmentaciones, hibridaciones (Appadurai 2001, Bauman 2007, Hannerz 1996) han mostrado con detalle el impacto de diferentes poderes desterritorializados sobre grupos y poblaciones locales. Aquí también los cuestionamientos han sido duros, especialmente debido al modo en que dichos análisis asumen las premisas del neoliberalismo como una fuerza inexorable (Graeber, 2001; Tsing, 2000), quedando presos de formas culturales que, bajo símbolos como "libertad", “elección”, "riesgos", “impactos" y "resistencias", naturalizan narrativas mayores y más totalitarias como la del mercado (Graeber, 2002: 1224) o la de la distinción local/ global anclada en el Estado-Nación (Gupta, 1998). En lo que hace al tema de este trabajo, otra debilidad notable de los enfoques culturalistas es que no brindan herramientas para analizar los trabajos concretos de los actores que deciden, intervienen, dirigen y administran infraestructuras y capacidades de movimientos. O si prestan atención a mercados, corporaciones, Estados e instituciones supranacionales, lo hacen tangencialmente y adoptando sus puntos de vista impersonales.

Un tercer conjunto de trabajos se ocupa de la relación entre procesos políticos e infraestructuras abordando las movilidades urbanas a partir de obras concretas inauguradas, anheladas, cuestionadas, impugnadas- concebidas como "efectos de Estado" (Harvey, 2005; Mitchell 1990; Trouillot, 2001). Estos trabajos han dado cuenta que la presentación de las infraestructuras como una técnica impersonal de gobierno manifiesta "la incertidumbre como una capacidad de Estado" (Dalakoglou y Harvey, 2012: 464), y que sus promesas de movilidad y conectividad son constitutivas de los 
procesos de “compresión espacio- temporal" (Harvey, 1998) del capitalismo contemporáneo que se presentan, sin serlo, como fuerzas globales impersonales de innovación tecnológica (Sassen, 1999).

Infraestructura y movilidad son contextos y productos del "trabajo político", incluyendo los procesos personalizados y burocráticos por los cuales aquellas llegan a ser inscriptas en agendas de gobierno y administración (Gaztañaga 2010a, Gaztañaga et al 2016). Muchos de los procesos de marginación y desconexión en las ciudades contemporáneas a menudo ocurren a través de la infraestructura, por ejemplo cuando las formas viejas se deterioran (Graham y Marvin, 2001), cuando un parque emblemático es patrimonializado según la lógica del urbanismo insular (Giglia, 2013), o cuando la construcción de vialidades de vanguardia consagran al uso vehicular independientemente del sector al cual se dirige su emplazamiento (Pérez Negrete, 2010). Las relaciones que la gente construye con ellas, como formas de poder humanas y no humanas, hacen asibles las abstracciones del neoliberalismo (Mains, 2012). Las obras articulan las historias de personas en poblaciones y comunidades concretas con las visiones abstractas de las leyes, narrativas nacionales de estadistas y la larga duración, donde el pasado adquiere la forma de trascendencia; por ello estudiar su cotidianeidad significa investigar la intimidad del poder en la vida humana y constituyen un locus privilegiado para la etnografía (Abram, 2014; Star, 1999).

Los diferentes enfoques y tendencias mencionados se verifican también históricamente. Durante la mayor parte del siglo XX se desplegó el moderno ideal de infraestructura donde el Estado monopolizaba la construcción o el control sobre los sistemas de infraestructura más importantes (Dalakoglou, 2016). Pero hacia fines de 1990 y los 2000, tras la caída del muro de Berlín y de la mano de recetas neoliberales de austeridad promovidas por gobiernos y organismos de crédito internacionales, se fue produciendo un pasaje generalizado hacia la promoción de la provisión de infraestructura pública en manos de asociaciones públicas y privadas. La crisis del capitalismo global que data desde la década de 1970 ha evidenciado el papel clave de las inversiones en infraestructura y su correlación con los procesos de "ajuste espaciotemporal" (Harvey, 2005: 100-103) a través de absorber el excedente de trabajo y capital en los sistemas territoriales vía inversiones de capital en proyectos de largo plazo o en gastos sociales como educación y/o la apertura de nuevos mercados. En la actualidad las infraestructuras físicas (sistemas de transporte y comunicaciones, parques 
industriales, agua y cloacas, vivienda, hospitales, escuelas, etc.) son consideradas como un sector de la economía capaz de absorber grandes cantidades de capital y trabajo. También es ampliamente reconocido que ello requiere de decisiones políticas de administraciones de gobierno, y de la mediación de instituciones financieras y/o estatales capaces de generar crédito. El estudio de la producción y provision de infraestructura pública revela que las dicotomías del tipo planificadores estatales/ usuarios ciudadanos, o capital estatal nacional /privado internacional conforman en sí mismas prácticas, lógicas e imaginarios que refuerzan el proyecto de la unidad en la fragmentación del Estado y de los múltiples intereses que rodean su desarrollo (que remite a comprensiones heterogéneas de la moralidad y patrimonialidad del Estado, incluyendo intereses transnacionales y procesos de privatizaciones). En Argentina, como en diferentes partes del mundo, las grandes obras pasaron de ser objetos de deseo (o rechazo), emblema del "desarrollo" (y sus bemoles), a ser tenidas como símbolo de acción política que, de la mano de las propias transformaciones de la gestión de lo público, encarnarían dos formas morales de gobernanza dicotómicas: corrupción y escándalo, o liderazgo y responsabilidad. Sin embargo, es de notar que en ambos casos, y lejos de lo propuesto por el neoliberalismo ortodoxo, el Estado jamás dejó la escena sino que profundizó su protagonismo.

Este trabajo busca hacer una contribución al estudio de los trabajos políticos puestos en juego en la producción social de la condición relativa de la escala urbana atendiendo a las experiencias vividas de una infraestructura vial provista y demandada al sector público y diversas agencias estatales. Focaliza en el proceso político tejido en torno de la construcción de un viaducto sobre el río Paraná entre dos ciudades: Paraná, la capital de la provincia de Entre Ríos, y Santa Fe, capital de la provincia homónima, actualmente vinculadas de manera física por un túnel subfluvial. Como recurso etnográfico y expositivo se centra en el análisis de un evento en el cual actores políticos gubernamentales y no gubernamentales debatieron acerca de los beneficios y perjuicios del futuro viaducto, y movilizaron controversias socialmente significativas en torno a prácticas y significados asociados con la imaginación y producción social de "lo urbano" y las escalas de "lo metropolitano". En términos metodológicos este trabajo se apoya en un conjunto de investigaciones antropológicas propias, desarrolladas desde 1999 en la misma zona del país en las cuales abordé la relación entre "obra pública" y "trabajo político" con un enfoque y metodología etnográficos. En lo que hace al 
relevamiento específico del proceso político en torno del "puente Santa Fe-Paraná", llevé a cabo trabajo de campo etnográfico desde 2012, desarrollando observación participante en diferentes eventos locales, interciudades y regionales. Realicé también una docena de entrevistas semiestructuradas a funcionarios de las Direcciones de Vialidad provincial y Nacional, de la cartera de Obras Públicas, de Santa Fe, y de Infraestructura y Servicios, de Entre Ríos, representantes de los Colegio de Profesionales de la Ingeniería Civil de ambas provincias, activistas de ONGs y asociaciones ambientalistas, y a especialistas de instituciones universitarias y entidades de la sociedad civil que reivindican saberes técnicos especializados, como empresarios y consultores. Finalmente, también recopilé y examiné documentación y publicaciones especializadas, gubernamentales y privadas, producidas por mis interlocutores y que circulan por canales tanto oficiales como informales (informes de gestión, cronologías, folletos y publicaciones de divulgación) y las notas periodísticas sobre la obra en medios de prensa.

\section{Dos maneras de llegar a un puente y atravesarlo}

Llegué a conocer el proyecto del puente entre las ciudades de Paraná y Santa Fe en el marco de una investigación etnográfica dedicada a estudiar la conformación de la Región Centro, un proceso de integración subnacional entablado por las provincias argentinas de Córdoba, Entre Ríos y Santa Fe (Gaztañaga, 2012). En este contexto diferentes actores políticos producían el "valor regional" de una miríada de obras públicas de infraestructura las cuales involucraban usos y apropiaciones del territorio y sus recursos en escalas diversas (municipales, provinciales, nacionales y de proyección internacional) y que remitían a cuestiones socialmente relevantes de alcances disímiles (autopistas, rutas y caminos, conexiones viales, hidrovías, dragados portuarios, energía eléctrica, telecomunicaciones, acueductos y gasoductos). El proyecto de construir un viaducto entre Santa Fe y Paraná para mejorar y ampliar la conectividad entre ambas capitales provinciales se remonta a la década de 1990, pero adquirió mayor relevancia alrededor del año 2012 cuando se convirtió en uno de los tópicos más importantes en los eventos institucionales de la Región Centro (Gaztañaga, 2016). Los funcionarios de los gobiernos y los participantes de los de los Foros de la sociedad civil (empresarios, universidades, trabajadores y profesionales) se referían al mismo asignándole un papel 
clave para la consolidación de la "integración física" de las provincias con el supuesto de que ésta impactaría positivamente en su desarrollo socioeconómico, junto al fortalecimiento del tendido ferroviario, el desarrollo de la Hidrovía del Paraná y las políticas de control de puertos deportivos y comerciales privados.

Hasta la fecha las obras no han comenzado (diferentes funcionarios estiman que esto ocurrirá hacia el 2019) pero sí han ido ocurriendo algunas transformaciones en su estatus proyectado; especialmente hacia mediados de 2014 cuando las autoridades nacionales elaboraron los términos de referencia para el llamado a licitación de la consultoría del proyecto ejecutivo y la designación de la consultora que sería la encargada de analizar las posibles trazas. En ese contexto, me interesó examinar desde un punto de vista etnográfico cómo impactaba ese movimiento hacia la concreción de la obra para los actores implicados en la "gobernanza local” (Borja y Castells, 1997; Carmona; 2015). Planifiqué entonces una campaña de trabajo campo con el objeto de relevar el estado de situación de la obra. Ese viaje se avizoraba como uno más entre tantos que había realizado para la investigación sobre la Región Centro, yendo desde la ciudad de Buenos Aires hacia las provincias para asistir a eventos políticos, lanzamientos, seminarios, charlas y reuniones. En esta oportunidad sin embargo, había otro movimiento que no estaba en mis planes y que empero me depararía la posibilidad más o menos inesperada de reorientar mis preguntas hacia los procesos políticos que producen la escala urbana.

Preparando la campaña de trabajo de campo, el desafío mayor era hacerme un lugar en las ocupadas agendas de mis interlocutores. No fue sencillo pero logré delinear una semana completa de actividades para investigar el mentado futuro puente. Dado mi interés por el proceso político regional, una de las entrevistas más importantes era a la intendente de Paraná, una de las principales figuras femeninas del peronismo entrerriano, ex senadora y diputada nacional, y dirigente del Frente para la Victoria, la fuerza política que desde el 2007 gobernaba la provincia. Sin embargo, el mismo día del viaje, apenas sentada en el avión y con la atención puesta en las indicaciones de la azafata de apagar los dispositivos móviles, sonó mi teléfono y una cordial voz desde la Secretaría Privada del municipio entrerriano me indicó "a la intendenta le surgieron unos compromisos y no va a poder recibirla". La desazón fagocitó mi ansiedad en un segundo. De nada sirvieron los intentos de reprogramar y los ofrecimientos de flexibles alternativas. Mabel se disculpó y agregó: “pero aprovecho y le aviso que mañana hay 
unas jornadas en la Universidad del Litoral que pueden interesarle. No quiero obligarla pero me parece que está relacionado con lo que usted trabaja”. Agradecida, le pedí los detalles. "A las 9, en el Paraninfo; va a estar gente del municipio que participó en las Jornadas Metropolitanas anteriores" (y mencionó al entonces secretario de Planeamiento Urbano a quien ya había entrevistado en varias oportunidades). Apuradamente le expliqué que debía colgar y que por favor me enviara el programa "se lo voy a escanear y se lo mando por mail". Aturdida por el inicio del despegue, mi descontento con la situación viró hacia mi propia estrategia analítica: había focalizado demasiado en los políticos y no me había enterado del evento. La intendente no asistiría pero valía la pena cruzar a Santa Fe. El castigo a mi miopía etnográfica era llegar a la capital entrerriana por la noche y tener que partir hacia la capital santafesina bien temprano por la mañana, cuando podría haber viajado allí directamente.

El viaje en avión en esa noche clara me dio la posibilidad de contemplar la vista magnífica del río y experimentar de otra manera la distancia y la cercanía entre ambas ciudades como una ondulante culebra acuática de luces tan imaginaria como real. En una hora ya estaba en tierra firme. El viaje en taxi, de la periferia al centro de la capital también fue revelador a su modo. El silencio absoluto del conductor -inusual para mí, acostumbrada a la dulce verborragia entrerriana- signó buena parte del camino, entre calles de tierra, terrenos vacíos, corrales de gallinas y casas bajas desperdigadas entre oscuros terrenos vacíos. Se rompió luego de pasar por el enorme edificio de Vialidad Nacional sobre la Avenida Almafuerte, cuando en el primer semáforo se produjo un encuentro con otro taxista. - ¿Tenés el celular del Ruso? - ¿Para qué, para pedirle el coche? ¡Comprate un teléfono! La respuesta era broma porque con el automóvil en marcha se las ingenió para anotar un número en un papel y alcanzárselo, contorsionando su torso fuera de la ventanilla de una manera algo aterradora. Tras semejante proeza, al fin se dirigió hacia mí por el reflejo en el retrovisor. "Es que esto es un pueblo todavía; yo no la conozco a usted pero conozco a alguien que la conoce". Y así comenzó una frenética narración: a los 18 años se fue a Buenos Aires, trabajó en un taller mecánico, se volvió porque no le gustó, se casó con su novia, tuvieron varios hijos, todos lo reconocen en el taxi y en su coche particular. Y al llegar a destino llegó el cliché que esperaba: "como dicen los vagos, pueblo chico infierno grande", pero con un remate inesperado: "acá para hacer trampa hay que ir a Santa Fe". 
Una vez acomodada en mi pequeña habitación del hotel sindical céntrico logré descargar el archivo adjunto que me había enviado la secretaria del municipio tras una docena de intentos y reclamos por la endeble conexión de internet: era una versión más detallada que la que figuraba en el portal de la universidad. El archivo era la invitación oficial de la máxima autoridad universitaria en hoja con membrete y número de nota, enviada una semana antes. El ingeniero firmante señalaba que la participación de la presidente municipal era importante dada la "relevancia de la temática en función del desarrollo regional y la conexión vial en el área metropolitana". La actividad era parte de un ciclo de debates que tenía por título "Hacia un desarrollo sustentable 2014" y había sido organizada por la Universidad Nacional del Litoral (UNL) a través de la Secretaría de Vinculación Tecnológica y Desarrollo productivo y las Facultades de Arquitectura y de Ingeniería, y por el Ente Túnel subfluvial, el organismo interprovincial encargado de la administración, control y mantenimiento del túnel. La jornada de apertura estaba anunciada como "La conexión vial Santa Fe-Paraná en el marco del Área Metropolitana" y se enmarcaban en los festejos del $45^{\circ}$ aniversario del Túnel, para lo cual eran invitados especialistas nacionales e internacionales.

Al día siguiente dejé el hotel a las siete y media de la mañana y caminé hasta la terminal de buses. Conozco de memoria el recorrido pero como una especie de hechizo ritual del trabajo de campo, suelo preguntar por el camino a las personas con las que me cruzo. En este caso, además, la sentencia del taxista de "pueblo chico..." resonaba contra el hecho de estar yendo a un evento que prometía "temas metropolitanos". Una señora mayor con la bolsa de la compra todavía vacía se ofreció a acompañarme unas cuadras, hasta que me despedí excusándome por el apuro; una pareja de jóvenes en motocicleta frenó amablemente para indicarme cómo llegar, y varias personas desconocidas - me saludaron "buen día" a la pasada. En la terminal, fue muy sencillo reconocer los puestos para comprar el boleto (lo mismo que a la vuelta, del otro lado) puesto que eran las únicas ventanillas donde se extendían largas filas y esperas. Esas mismas personas luego se saludaron con el chofer usando sus nombres de pila, dejando entrever cierta cotidianidad del encuentro.

Actualmente el túnel provee el modo más eficiente y rápido para ir y volver de una ciudad a la otra. Su trayecto lo realizan diariamente miles de personas y toneladas de bienes, en transporte público o particular; siendo este último más del $80 \%$ del total según las estadísticas del 2014 elaboradas por el ente intergubernamental encargado de 
su administración. Atravesar el caudaloso enorme Paraná de manera subterránea es fascinante. La cota más profunda es de 29,51 metros con lo cual el cruce es realmente un viaje subacuático. Entrando desde la vera entrerriana en la avenida Gobernador Uranga, pasando el Club Náutico, la luz del sol se pierde en pocos segundos y hay que acostumbrar la vista a la iluminación eléctrica de los 4.200 tubos fluorescentes de 36 watts que lo recorren. Son en total tres kilómetros de túnel y veintidós de una autovía que atraviesa el río engalanada de rojos mojones (numerosos altares para el santo popular Gauchito Gil, emplazados a lo largo de la Ruta Nacional 168). En la capital santafesina, el camino lleva a la intersección con la Ruta Nacional 11 y atraviesa las islas de La Guardia, Cañas, El Timbó y Santa Cándida. Cerca de 12.000 vehículos de diferente porte lo transitan a diario desde hace décadas, pero desde 2005 se fue verificando una suba anual constante coincidente también con el aumento de la plaza automotriz: de 3.034.160 vehículos anualmente hasta 4.284.339 en 2014. Para los organismos oficiales encargados de la administración y mantenimiento del túnel, estas cifras revelan la importancia de un nuevo enlace vial y del "área metropolitana Santa Fe-Paraná”, la cual en un radio de $25 \mathrm{~km}^{2}$ alberga cerca de un millón de personas.

Como obra pública de infraestructura, el "Túnel Subfluvial Uranga-Begnis" tiene su propia y fascinante historia. Siguiendo la cronología ${ }^{2}$ que ofrece el Ente Interprovincial encargado de su administración, las gestiones de conexión comienzan con el siglo XX, reconociendo como primer hito político a la presentación que hiciera un senador nacional entrerriano de la Unión Cívica Radical (UCR) en la década de 1930. Durante 45 años el proyecto de construir un puente o un túnel quedó reducido a diferentes expresiones de interés y desinterés por parte de los sucesivos gobiernos nacionales, hasta que el Decreto N. 7122/56 emitido por el gobierno de facto de Pedro Aramburu declaró el proyecto del túnel de Interés Nacional. Pero el impulso fundamental para la concreción de la obra colosal y pionera en el mundo fue la rúbrica del tratado de construcción, el 15 de junio de 1960, entre los gobernadores Carlos Sylvestre Begnis y Raúl Lucio Uranga, de Santa Fe y Entre Ríos respectivamente. Ambos gobernadores revistieron actuaciones en diferentes frentes políticos, incluidos el radicalismo y el peronismo, y en homenaje a sus esfuerzos por impulsar la obra entre

\footnotetext{
${ }^{2}$ Disponible en http://www.tunelsubfluvial.gov.ar/ y https://issuu.com/santafeciudad/docs/aulaciudad_17vf
} 
1958 y 1962, el túnel fue rebautizado con sus nombres. ${ }^{3}$ Como otras obras infraestructuras del mismo período histórico de la Argentina, la fundamentación del túnel estuvo inspirada en la metáfora del "desarrollo" y en particular el ligado a fortalecer el comercio, el transporte y la mejora de la calidad de vida de los habitantes. En ese entonces, la opción de construir un túnel en contraposición a un puente se fundamentó en varios aspectos: la duración prolongada de la obra (un puente tiene una vida útil más reducida y la fatiga del material aumenta los costos de mantenimiento), la ingeniería que posibilitaba una transitoriedad constante y fluida sin obstaculizar la navegación del Paraná (un puente lleva pilares o columnas que la obstaculizan), y la absorción de los costos (los impuestos estipulados para las obras sobre la superficie terrestre pertenece a la jurisdicción nacional). Su construcción demandó siete años y atravesó varios cambios de rumbo de la vida institucional democrática argentina, en cuyo transcurso el presidente Arturo Frondizi colocó la Piedra Fundamental en la isla Santa Cándida en 1962, y nuevamente un gobierno de facto, el de Juan Carlos Onganía, fue el encargado de inaugurarla el 13 de diciembre de 1969.

El Túnel Subfluvial fue la única conexión física entre ambas provincias hasta 2003, cuando se inauguró el puente Rosario-Victoria, emplazado cerca de 120 kilómetros al sur por el lado entrerriano y 170 del lado santafesino. Gobiernos, especialistas, consultores académicos y entidades empresarias celebran estas obras apelando a la importancia geopolítica, especialmente su "rol estratégico" en un eje que trazan a partir de intersectar el Corredor Bioceánico Central, que involucra a Brasil, Argentina y Chile, con la Hidrovía Paraná-Paraguay, que incluye a Argentina, Paraguay, Bolivia y Brasil (Gaztañaga, 2010b). Cada cruce, sin embargo, ostenta características propias. El túnel recibe el doble de vehículos que el puente RosarioVictoria (durante el 2014 circularon más de 4 millones de vehículos por el primero y el $82 \%$ del total autos; por el segundo circularon en promedio 2.300 .000 vehículos, el $70 \%$ autos). Y mientras que atravesarlo tiene un costo de $\$ 13$, que se puede abonar en ambas cabeceras, cruzar el puente entre Victoria Rosario cuesta cuatro pesos menos, implica el triple de kilómetros y sólo se abona en la margen rosarina (la tarifa está congelada por

\footnotetext{
${ }^{3}$ El Túnel fue originalmente bautizado Hernandarias en honor a Hernando Arias de Saavedra, gobernador del Río de la Plata y Paraguay, hacia fines del siglo XVI y comienzos del XVII, como homenaje a quien se considera el primer conductor de los criollos en los dominios de la corona española en América. Una veintena de años más tarde, la Resolución 196/90 del Consejo Superior Interministerial del Túnel Subfluvial y las leyes 11554 y 9350 de las legislaturas santafesinas y entrerrianas, respectivamente, propusieron honrar a los gobernadores que promovieron la obra.
} 
disposiciones del ente nacional de control). Estos indicadores esgrimen especialistas políticos y técnicos de ámbitos públicos y privados para especificar la relevancia social y territorial del "nuevo puente". En particular avanzan la importancia de la zona "metropolitana" que vendrían a producir conjuntamente Paraná y Santa Fe, lo cual contrasta con el caso de las ciudades de Rosario y Victoria que están más alejadas (producto de la propia orografía del Paraná y el valle fluvial a esa altura) y signadas por otros tipos de distancia: casi un millón de habitantes en el lado santafesino contra menos de 40.000 en el entrerriano.

La comunicación e intercambio entre Paraná y Santa Fe es masiva y permanente. Durante los días laborales de la semana, la mayoría de los usuarios del transporte público son trabajadores y estudiantes. Hay cerca de un centenar de servicios, directos o con paradas intermedias en diferentes frecuencias que van desde media hora a 10 minutos y que los domingos y feriados se espacian a más de una hora. Al menos hasta 2015 dos empresas realizaban el trayecto con una tarifa accesible, estatalmente subsidiada de un viaje simple $\$ 7,00$ para estudiantes y jubilados, y $\$ 8,00$ para todos los demás pasajeros. Ese martes por la mañana viajé en un micro atestado de estudiantes de colegio secundario en un bullicio de carcajadas, mochilas contra el piso y videos musicales que sonaban desde decenas de teléfonos celulares. En una hora llegué a la capital santafesina y en quince minutos más a pie, bajo un plácido sol primaveral, estaba en el Paraninfo de la Universidad Nacional del Litoral (UNL).

\section{El evento metropolitano}

Llegué a tiempo para ponerme en la fila de la inscripción junto a los últimos del centenar y medio de personas que se dieron cita ese día, en su mayoría estudiantes universitarios. En el hall de entrada, tres jóvenes se encargaban de tomarnos los datos, volcarnos en una planilla, entregarnos una carpeta con el logotipo del Túnel Subfluvial y un bolígrafo con el logo de la Universidad, y avisarnos que al final recibiríamos el certificado de asistencia. La jornada comenzó con una puntualidad inusitada lo cual me llevó a dudar sobre el carácter político del evento. Acostumbrada a largas dilaciones ya que los políticos importantes no despliegan públicamente sus apariciones si no en lugares colmados de gente y con los medios de comunicación como testigos - descarté que los presidentes municipales se fueran a dar cita. Recordando otros eventos 
académicos a los que he asistido, decidí sentarme hacia un costado del semicírculo del anfiteatro donde pudiera leer el libro que llevaba conmigo llegado el caso de que la cuestión técnica de la obra superase mi capacidad de entendimiento y concentración. Pero la palidez neoclásica del salón no duraría más que unos pocos minutos, ya que un acotado pero ruidoso tumulto de cámaras y agentes de seguridad privada dio paso a los intendentes que entraron saludando sosegadamente entre los flashes.

Una presentadora y una intérprete de lenguaje de señas dieron la bienvenida y saludaron a los "invitados especiales" por nombre y cargo. De acuerdo con el orden establecido en el programa, abriría el representante de la universidad, luego los dos presidentes municipales y por último seis disertantes. El programa presentaba una clara intención temática coherente con la afiliación de los venidos de afuera y las temáticas sobre las cuales versarían. Las dos primeras exposiciones serían de "invitados de afuera": un Doctor en Arquitectura de la Universidad de la República Oriental del Uruguay (sobre el área metropolitana) y un Ingeniero Coordinador General de Vialidad Nacional Argentina (sobre el corredor bioceánico). Y las últimas cuatro pertenecían a una mesa redonda de "especialistas locales" (dos académicos de la UNL y dos de los gobiernos, uno por cada municipio). Dentro del impoluto y solemne auditorio semivacío, el escenario parecía minúsculo: una mesa alargada en el centro cubierta con una tela oscura y sillas; detrás una enorme pantalla enmarcada por un cortinado abierto, y a la derecha, la bandera argentina. En un cálculo generoso las mujeres éramos un $20 \%$ del total, y un clivaje etario signaba la disposición en el espacio: los jóvenes en los asientos del fondo y los adultos y mayores, adelante. El público presente escuchó atento y en silencio, y aplaudió debidamente cada intervención.

La presentación a cargo del Secretario General de la Universidad giró en torno de la temática metropolitana, a la cual inscribió en un breve y conciso arco histórico político dejando en claro cuáles eran sus interlocutores en el evento y más allá del mismo. El abogado identificó a los gobernadores que promovieron el túnel como "visionarios capaces de comprender lo que hoy nos estamos planteando" y expuso su visión del proceso local “donde cobra más fuerza la idea de Área Metropolitana en el hecho de que los territorios no pueden ser gestionados independientemente". Estas consignas fueron retomadas por todos los expositores, pero no para ponerlas en práctica, sino como practicantes rebeldes de una extraña coreografía que a cada paso iría dejando en claro el escaso acuerdo entre los danzantes. 
La intendente de Paraná tomó la iniciativa, cuestionando de manera sutil la propuesta del evento: “el aniversario del Túnel Subfluvial, más que una problemática, es una excelente excusa para que podamos abordar temas sustantivos como es la comunicación entre los pueblos". Y al referirse a la obra del puente subrayó sus condiciones de producción, recordando "el trabajo de quienes venían haciendo aportes para la nueva obra: en la integración de comisiones, firma de convenios, debates de diseños". Este trabajo localmente identificable era "desde los municipios, los gobiernos provinciales y en el marco de un sostén real y efectivo de nuestro Gobierno Nacional en esta interconexión". Y para sellar su propio trabajo de insertar la importancia de la obra en un proceso escalar de niveles geopolíticos, señaló que estábamos en "un contexto que nos trasciende", el de la integración latinoamericana, la demanda de los BRICS $^{4}$ de conexión con oriente y el desarrollo Sur-Sur. Aplausos mediante, tomó la palabra el presidente municipal de Santa Fe (del Frente Progresista, Cívico y Social). Este abogado y actual Presidente del Comité Nacional de la Unión Cívica Radical, mantuvo el tono crítico de su par entrerriana pero su discurso fue más extenso y polémico, especialmente al explicitar dudas respecto del carácter prioritario de esa nueva conexión. Como contraste, ofreció las "tres premisas generales" de su gestión: aprovechar las infraestructuras existentes, las inversiones ya hechas; articular con las otras decisiones de infraestructuras que están en camino, como el nuevo puerto de Santa Fe y las decisiones urbanísticas de ambas ciudades, y finalmente tener presente que estamos interviniendo en el ambiente y que eso puede generar nuevos riesgos. Y cuando destacó los contextos políticos de la nueva obra, se mantuvo en una escala más próxima: "convencidos de la necesidad de trabajar en la integración y volver a instalar en la agenda en primer lugar a la integración de ambas ciudades y ambas provincias".

Ambos intendentes se retiraron raudamente junto con la mayor parte de los periodistas que cubrieron el acto. Pero el evento recién comenzaba, al igual que el desmoronamiento de toda política de ontología metropolitana. El primero de los expositores invitados fue un especialista en ordenamiento territorial y desarrollo urbano uruguayo, quien abordó directamente la diferencia entre un área metropolitana "existente" y su "construcción", explicando que ésta requiere ingeniería intelectual y organizar gobiernos además de técnicas conectivas en el territorio. Con más de treinta

\footnotetext{
4 Acrónimo acuñado en el 2001 por el grupo Goldman Sachs para hacer referencia a las economías emergentes de Brasil, Rusia, India y China que marcarían el devenir de la política económica global de los siguientes 50 años.
} 
diapositivas fue proyectando en la enorme pantalla los "peligros de tomar lo metropolitano como un a priori ideológico" y de "trasladar metáforas de la "globalización a los contextos locales". Y como si eso fuera poco, resumió un pequeño trabajo que había producido especialmente para el evento en el cual rastreó las "percepciones mutuas" de santa Fe y Paraná dentro del último Plan Estratégico territorial elaborado por las provincias argentinas. No solamente aquellas eran desiguales, en detrimento de los entrerrianos sino que el problema era que estamos ante "un huevo con dos yemas, pero no unidas por proteínas sino por un núcleo vacío: por agua". Esa metáfora, que se le había ocurrido la noche anterior durante la cena en la ciudad de Santa Fe, terminó siendo mucho más poderosa que las fotos satelitales que usó para apoyar su argumento.

Luego de la entretenida presentación del uruguayo, el siguiente expositor advirtió que iba a utilizar un tono "más duro, más técnico". Este ingeniero de Vialidad Nacional (ente autárquico del Poder Ejecutivo Nacional, jurisdicción en la que recae la obra del futuro puente) venía a contarnos su experiencia como coordinador técnico del Ente Binacional Túnel de Agua Negra, el monumental paso vial que cruzará la cordillera de los Andes a la altura de la provincia argentina de San Juan y la zona de Coquimbo en Chile. Las imágenes y explicaciones de la fastuosa ingeniería del futuro doble túnel fueron impactantes, al igual que los pormenores y anécdotas del arduo proceso de planificación y negociación entablado por los dos países. Evidentemente su exposición pertenecía a otro plano político y económico pero advirtió que podía ser de interés para futuras dimensiones (comercial, productiva, turística, ecológica, socioeconómica e inmobiliaria) del "proceso de metropolización". Y al recalcar la importancia de "ir consolidando físicamente la integración materializando las obras que hacen al Corredor Bioceánico Central”, ingresó al viaducto en el ámbito de los corredores IIRSA5, de manera significativamente familiar cómo la mandataria entrerriana lo había hecho poco antes: la obra era crucial para consolidar los 2472 kilómetros desde Porto Alegre, en Brasil, hasta Coquimbo, en Chile, pasando por lo que sería el Santa Fe-Paraná, la autopista de Córdoba y hasta San Juan atravesando los Andes por el Túnel Agua Negra.

\footnotetext{
${ }^{5}$ La iniciativa de Infraestructura de Integración Regional Suramericana (IIRSA) es una plataforma de obras viales y energéticas, surgida como soporte del ALCA y luego integrada a UNASUR, que tiende a reforzar la "territorialidad neoliberal" (Ceceña et al., 2007; Olivo, 2008).
} 
Durante la breve pausa de café - un sencillo pero suculento servicio de catering instalado en las galerías de uno de los patios interiores del edificio - conversé con algunos entrerrianos del Foro de empresarios de la Región Centro, quienes habían cruzado a la capital vecina convocados por el tema de los corredores IIRSA. A los veinte minutos regresamos al recinto para el cierre. Era el turno de los especialistas locales, dos por la universidad y uno por cada municipio. De la rectangular mesa redonda, la primera en exponer fue una arquitecta, responsable del programa Taller de Estudios Metropolitanos y de proyectos en la Secretaría de Ciencia y Tecnología de la universidad; le siguieron un arquitecto, Subsecretario en infraestructura de la Municipalidad de Paraná (el Secretario que figuraba en el programa estaba de viaje en Europa); un ingeniero, Director del Programa Ambiente y Sociedad de la Secretaría de Extensión universitaria, y otro arquitecto, Secretario de Planeamiento Urbano de la Municipalidad de la Ciudad de Santa Fe. Antes de comenzar se excusaron en que cada uno realizaría una exposición resumida de lo que pensaban tratar "porque se había hecho muy tarde". Sin embargo, bastaron pocas alocuciones para dejar en claro que el debate era inevitable: un cisma de sentido, percepción e imaginación de lo urbano fue instalándose a medida que desarrollaron sus intervenciones.

Los especialistas de la universidad, a diferencia de los gubernamentales, parecían dar por sentada la existencia de una región metropolitana en la medida en que sus diagnósticos y recomendaciones asumían dicha problemática. La arquitecta, por ejemplo, señaló que allí "lo metropolitano significaba dos ciudades intermedias" y que había que ir "de la línea al plano" para tomar en cuenta las especificidades de ese territorio con cerca de ochenta asentamientos. El arquitecto que la siguió, abordó el tema desde la situación actual de una población agobiada por la ausencia de políticas de estado y reunida por traumáticas experiencias de inundaciones, especialmente en la margen santafesina. Ambos propusieron que el ordenamiento territorial de la integración entre los núcleos urbanos debía estar conceptualmente planificado y proteger a los núcleos ecológicos más sensibles. Sus observaciones de los costos y riesgos que traería aparejada la nueva infraestructura (medioambientales, socioeconómicos y de reconfiguración territorial) tenían como interlocutores a los gobiernos: demandas de "articular" la toma de decisiones y cómo iban a "legislar" sobre la ocupación formal e informal de tierras inundables, el aumento de la movilidad y el 
transporte de personas y mercancías, y las actividades comerciales y recreativas como el turismo; porque el "desarrollo sustentable" es política de Estado.

A su turno, los especialistas de los gobiernos actuaron sus movimientos girando sobre la vocación y el trabajo políticos. El responsable por el municipio paranaense comenzó destacando que "la voluntad de integración metropolitana siempre ha estado está en la agenda desde el lado entrerriano, porque nos hemos sentido aislados durante mucho tiempo". Hilvanó la "responsabilidad política" con la "escala humana" del proceso de metropolización apelando a su historia personal: "nací en el año 1971 y viví siempre en Paraná, estudié en Santa Fe, viajé casi 10 años todos los días a la facultad, tengo muchísimos amigos en Santa Fe". Además de reseñar su trayectoria de trabajo con profesionales y organismos públicos santafesinos agregó otro elemento personal pero esta vez para subrayar un contraste: "para mí, venir a Santa Fe es una cuestión de todos los días; mi mamá, mis abuelos cuando viajaban en las lanchas y nunca sabían si llegaban o si volvían”. Y hacia el final regresó vacilante pareciendo contradecir sus pasos: "en la última década con la autovía Paraná-Santa Fe nos hemos acercado de una manera inconmensurable pero las nuevas obras de infraestructura no solucionan la conectividad". Una tarea de gobierno era "pensar la cuestión metropolitana".

El arquitecto que representaba a la municipalidad de Santa Fe también eligió la dimensión personal para comenzar: "mi madre es entrerriana y soy de aquellos que cruzaban la balsa a cadena y después la otra balsa para viajar a Concepción del Uruguay". Pero en un giro poético sobre la experiencia del río "siempre amenazándonos" hizo explícitos dos temas que en las intervenciones previas aparecieron de maneras más veladas. Por un lado que "Santa Fe y Paraná nunca va a ser San Pablo ni Toronto, que son áreas metropolitanas de municipios que se unificaron a partir de un acto jurídico". Por otro lado, que "nosotros entramos en este umbral central censal de un millón de habitantes; la analogía es con Rosario o Córdoba, pero ellos sí tienen continuidad territorial". Así, planteando al área metropolitana como una construcción jurídica y detectando la (dis)continuidad territorial complejizó la interpretación del nuevo enlace vial y lo que era inevitable: politizar más aún el tema. "La determinación de un área metropolitana es un acto político" sentenció, y para ilustrarlo trajo a la mesa otras acciones similares: "antecedentes que datan desde el año '98, cuando se crea la Región Centro y se le da vida a todo el proyecto del corredor bioceánico"; también fue "decisión política", cuando Uranga y Begnis hicieron el túnel 
"posicionaron geoestratégicamente a la ciudad; proyecto abortado por las discontinuidades políticas que tuvo Argentina a partir del año '66”. No obstante, la consigna no era solo que "la responsabilidad es política" (algo que ya habían señalado los intendentes) sino "la validación social, que hay que militarla". Para explicar este punto apeló a un significativo ejemplo: ¿cómo hace un taxista de Santo Tomé o el de Recreo o el de San José de Rincón para trabajar en Santa Fe en un pie de igualdad con el taxista local; el taxista de Oro Verde que quiere trabajar en la ciudad de Paraná? "Estos son los problemas de la gente", se sinceró. Y como si estuviera manteniendo una discusión sobre la noción de "democracia de proximidad" (Le Bart \& Lefebvre, 2005; $c f$. Landau, 2014) destacó que si había una "orfandad de la fortaleza como área metropolitana" ello tenía que ver con algo más que la conectividad: "a medida que uno empieza a hilar finito va entendiendo que la sumatoria de proyectos no es la conformación de un todo como sistema urbano".

Tras los aplausos a los expositores fue invitado al escenario el Director del túnel subfluvial para cerrar el evento de una manera institucional. Su breve intervención, no obstante, fue mucho más que eso. En principio porque consideró que el puente podía convertirse en "un registro histórico de una utopía hecha realidad" al igual que el túnel. Haciendo gala de "cuarenta y cinco años de gestión ininterrumpida" de esta obra, recuperó los saberes, experiencias, organizaciones y proyectos en torno al nuevo puente, considerando que ya había una "madurez para pasar de la visión a la acción”. ¿Cuál acción? la de "articular una escala metropolitana". Pero su mirada no era, como podría imaginarse, de aleccionamiento institucional desde el pasado, sino que se tendía hacia el futuro, el tiempo de los planificadores: "las decisiones de gobierno tienen que ver con que también cambian los ámbitos y los momentos políticos; los gobiernos locales hoy tienen una presencia que antes no tenían”. Y al destacar que para materializar un puente o un túnel se requerían "articulaciones políticas, proyectos políticos", selló la jornada, celebrando la presencia de los dos intendentes: "necesitamos liderazgos que nos den la posibilidad de que toda la articulación pública privada tenga un camino para ser recorrido". 


\section{Aporías urbanas}

Siguiendo la distinción que propusiera Fredrik Barth (2000) entre evento o aspecto externo del comportamiento y el acto como su significado intencional e interpretado, para las personas todo evento es potencialmente un acto que comienza antes y termina después en otros sitios personales y sociales. Y en ese sentido, son también construcciones analíticas que el investigador delimita con su presencia y su interés de investigación, y que construye como "situaciones sociales" que abstrae del flujo de la vida social (Gluckman, 1958: 9; Devons y Gluckman, 1964: 158). Por esta razón de honradez metodológica, debiera señalar que traicioné (¿en un arrojo de animismo?) la lealtad de mi grabador y que para (re)construir el evento me basé más en mis registros de las formas verbales y no verbales de la acción, y en diferentes instancias de observación con participación y de entrevistas que superan la estricta delimitación del acto en la UNL. Esto que podríamos llamar una necesaria edición etnográfica responde, sin embargo, a la reelaboración de los objetivos de mi trabajo (examinar la relación entre esta infraestructura pública y los procesos políticos locales como efecto estatal) a la luz de las maneras en los actores sociales produjeron controversias socialmente significativas de la relación entre el puente entre Santa Fe y Paraná y la metropolización.

El evento dejó al descubierto una heterogeneidad de incumbencias, axiologías, deseos, temores, propuestas, interrogantes, observaciones y prescripciones, que, además de expresar la porosidad de trayectorias y posicionamientos de sus protagonistas, escenificó que estos imaginan una obra pública de infraestructura de una manera indisociable a cómo imaginan otros contextos. El "nuevo puente" no sólo incorpora diferentes tipos de procesos estatales en y a través de diferentes escalas urbanas sino que su proyección remite a procesos ideológicos, económicos y jurídicos que incluyen a las coyunturas políticas inmediatas. Toda esta coreografía espástica y disonante puede ser considerada en conjunto como parte de un proceso de producción de totalidad social relevante.

Durante el trabajo de campo pude tomar conocimiento de que el peronismo entrerriano ya estaba para ese entonces trabajando en el trabajo de armado de la campaña para las elecciones de 2015 en las cuales se renovaban cargos ejecutivos y legislativos en toda la Argentina. El gobernador entrerriano, Sergio Urribarri (2007-11 y 
2011-15, FPV), se perfilaba como uno de los posibles candidatos presidenciables del Frente Para la Victoria. Este tema fue subrayado por varios de mis entrevistados, como un dato relevante de la política del puente. Particularmente, en el hecho de que unos meses antes se había realizado la apertura de sobres de la licitación $\left(\mathrm{N}^{\circ}\right.$. 06/14) de los estudios de traza y del proyecto ejecutivo del puente en la Casa de Gobierno entrerriana. Los funcionarios nacionales que lo encabezaron - secundados por diferentes funcionarios de ambas provincias - subrayaron en esa oportunidad el compromiso del Estado Nacional de tomar a la Obra Pública como una inversión y no como un gasto, destacando los valores del gobierno nacional de "una Argentina con voluntad federal, para todos". Localmente fue leído como la ratificación de otros puentes, ya que el 25 de junio del año anterior, en el marco de los festejos por el bicentenario de la ciudad de Paraná, la presidente argentina Cristina Fernández había alabado la "lealtad" del gobernador entrerriano y anunció su "decisión” de realizar el futuro enlace, advirtiendo, en un tono de comicidad: "no los voy a dejar que le pongan de nombre Puente BonfattiUrribarri". 6

Además de la campaña política electoral, el puente se inscribe en el escenario abierto por la última reforma de la constitución nacional de 1994, en la cual se hicieron más laxas algunas condiciones para la toma de crédito internacional y la aplicación de un enfoque de descentralización política y administrativa en el territorio. Esta reforma complejizó criterios y mecanismos institucionales y de gobierno (Escolar et al., 2004) y en muchos casos permitió acercar a municipios y nación "puenteando" a las provincias (Gaztañaga, 2013). A nivel del desarrollo de políticas públicas, ese contexto era también el del auge de ciertas metáforas conceptuales relativas a la "integración” como respuesta a la "globalización", en el cual surgirían diversos procesos de integración regional asociados al MERCOSUR (Rosato, 2010). Estas diferentes escalas de acción aparecieron condensadas en el evento pero no 'escalarmente' sino de una manera entramada con la praxis. Por un lado, la obra fue inscripta en el Programa IIRSA, en el trazado de un corredor bioceánico, que en Argentina impulsan conjuntamente las provincias de la Región Centro, San Juan y La Rioja. Por otro lado, diferentes actores del sector público y privado destacaron que el proyecto no solamente beneficiará a las provincias y ciudades afectadas físicamente por la conexión sino también para sustanciar la integración subnacional de la Región Centro. Y finalmente, que la obra

\footnotetext{
${ }^{6}$ Diario Uno de Entre Ríos, 26 de junio de 2013 http://www.unoentrerios.com.ar/la-provincia/cristinaanuncio-que-se-hara-el-puente-parana-santa-fe-n909089.html (último acceso, 20/09/2917)
} 
consolidará la "integración metropolitana” de Paraná y Santa Fe, no sólo al conectar los paisajes humanos y ecológicos inmediatos de su traza sino también en un sentido político territorial, por ejemplo, vía el proyecto de coordinar las sesiones legislativas de los respectivos concejos deliberantes de ambos municipios. Mientras tanto, entre las escalas ausentes del evento se destacó la cuestión concreta de los detalles de la traza definitiva, el emplazamiento de las bajadas $\mathrm{y}$ el estudio de los impactos medioambientales de la obra. Estas preocupaciones son las que diversas organizaciones no gubernamentales de ambas costas vienen abordando en estudios y relevamientos artesanales; un trabajo que disfruta de escasa y por momentos nula visibilidad en los medios de comunicación locales.

En este "palimpsesto" escalar (Gravano, 2005: 35) del trabajo político es posible advertir un aire de familia entre lo urbano y lo metropolitano como operadores simbólicos que articulan la geopolítica de la imaginación y la administración (Trouillot, 2011) con la producción de formas abstractas de disociación (Eriksen, 2014). Pero quisiera destacar que no es lo mismo tomar estas operaciones como metáforas del espacio que como metáforas temporales. Las primeras son el ámbito por excelencia de los teóricos del planeamiento urbano y de los geógrafos. Los antropólogos, en cambio, suelen subrayar más la importancia las segundas (Guyer, 2007; Bear, 2014). El enfoque antropológico de la temporalidad de las infraestructuras ha sido fértil para zanjar algunos inconvenientes que trae aparejada la espacialidad como única vía para estudiar las obras de infraestructura, ya que permite dejar de verlas como productos (los proyectos y sus diseños prometidos) y dar cuenta, en cambio, del planeamiento como una performance utilizada por actores concretos para organizar las sociedades en el presente. Dado que la orientación al futuro es uno de las dimensiones de realidad y necesidad que parece tornar irresistibles a las grandes obras de infraestructura, conforman un sitio para observar cómo se practican las relaciones de poder y control en los intentos de ordenar el mundo social a través del tiempo (Abram, 2014; Abram y Weszkalnys, 2013). El puente Santa Fe-Paraná no escapa a esta tendencia social e ideológica que hace de la obra un engranaje material temporal de la 'labor de conexión', a través de los trabajos políticos de diferentes actores ocupados en investigar, escribir, difundir, legislar, noticiar, llevar a los medios de comunicación, celebrar, negociar y, obviamente, participar de "jornadas metropolitanas". Estos trabajos no miran hacia un horizonte único sino que, al decir del director del túnel subfluvial, remiten al de "la 
utopía hecha realidad": su signo material e imaginario es el futuro en diálogo con el pasado y en las dinámicas de poder del presente.

Ahora bien, una pregunta que surge del análisis es ¿en qué medida la necesidad de una "nueva" obra, complementaria al Túnel, construye, proyecta o ratifica una “nueva” escala urbana "metropolitana”? Atendiendo a sus características demográficas, funcionales y adscriptivas, las capitales de Entre Ríos y Santa Fe caerían dentro de la clasificación de "ciudades intermedias" (Llop y Usón, 2014). Según el censo nacional de 2010, Santa Fe se ubica como la octava ciudad de la Argentina, con 650.000 habitantes, y Paraná se posiciona en decimocuarto lugar, con alrededor de 247.000. Ambas son centros políticos, administrativos y proveedores de servicio que extienden su influencia en áreas de aglomeración que ascienden a poblaciones de 753.073 y 273.000 habitantes. Pero esta clasificación que oscila entre lo normativo y lo operativo es problemática ya que en la Argentina el 95\% de la población reside en aglomeraciones "urbanas" y las tipologías oficiales del Estado sobre lo urbano se erigen a partir de una distinción con los contextos "rurales" en base a la demografía (Urriza y Garriz, 2014). Este sesgo complica aún más las cosas cuando consideramos que los estudios urbanos, incluyendo el de las infraestructuras, han tendido a concentrarse en grandes aglomerados como Córdoba, Rosario y el AMBA (Área Metropolitana de Buenos Aires), con lo cual el rango "medio" parece más tributario de definiciones arbitrarias que descriptivas o funcionales (¿cómo aunar la profunda diferencia demográfica entre 50.000 y poco menos de un millón de personas?).

Para pensar la relación del nuevo puente y la nueva escala metropolitana, resulta más productivo considerar cuáles son los "imaginarios que ponen a prueba la estandarización de los indicadores de escala del espacio" (Gravano, 2016: 70). Estos son los que permiten examinar la lógica escalar como una característica decisiva del Estado y sus agencias relacionadas en su capacidad de controlar, ordenar y jerarquizar el territorio. Por esta razón, en lugar de agotar por la negativa la fiabilidad o no de las clasificaciones de las ciudades intermedias, quisiera traer aquí una metáfora conceptual que remite en esencia e imaginación al concepto de puente. Me refiero al concepto de aporía, que en la filosofía griega antigua refería a lo que provoca incertidumbre y perplejidad, a lo insoluble en un razonamiento (el objeto del mismo o su

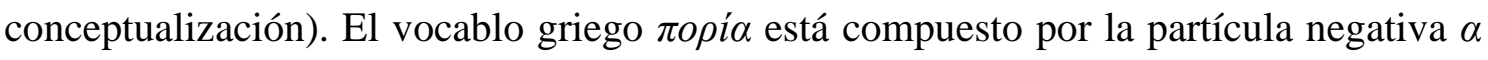

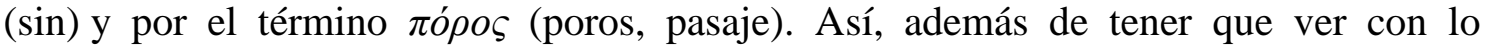


irresoluble, referencia la ausencia de camino, el impasse y la dificultad para continuar con la marcha; es el opuesto complementario del puente.

La aporía, como la ironía, era un recurso de la mayéutica socrática que se constituyó en un desarrollo filosófico con Platón y Aristóteles. Los primeros diálogos platónicos que intentaban definir alguna cualidad humana como la virtud o el valor, tenían carácter aporético: a través de su tratamiento desenmascaraba preconcepciones y razonamientos errados pero sin arribar a una resolución última. Para Aristóteles, la aporía hacía referencia a la igualdad de las conclusiones contrarias; sus ejemplos más célebres son los sofismas de Zenón de Elea que conforman la base de los argumentos acerca del movimiento en la Física (Cavallar, 2011). Y si bien las aporías del discípulo de Parménides (i.e. el movimiento es lógicamente imposible) fueron cuestionadas por estar basadas en una concepción del movimiento como suma de estados de reposo, sus conclusiones tuvieron la importancia de poner sobre el tapete otras preguntas que hasta el presente conforman núcleos de preocupación contemporáneos, como el estatus gnoseológico de la relación entre las partes y el todo, la dialéctica y el sentido político de la contradicción. ${ }^{7}$

Los alcances conceptuales de la aporía no se agotan en esta apretada síntesis ni en la cuestión del movimiento. De cara a este trabajo, significa la posibilidad de servirnos de al menos dos procedimientos diferenciables. El ya mencionado carácter heurístico, como herramienta para pensar, describir, analizar problemas sociales. Y el que tiene que ver con el carácter sintético, analítico, de la aporía como una modalidad de conocimiento que trastoca la ontología de los cimientos relativistas en el reconocimiento de la ambigüedad comunicativa (Carrithers, 2014). Presenta también la ventaja de superar el supuesto de que, a diferencia del espacio, el tiempo se presentaría huidizo y lábil a la observación, y que solo podemos pensarlo a través de metáforas de lugares. Si bien todo esto puede sonar algo abstracto, lo que quiero subrayar es que la empresa antropológica basada en la etnografía reúne ambos, y que, puestos en relación, fortalecen la labor interpretativa.

\footnotetext{
${ }^{7}$ Para los pensadores marxistas ha sido un lugar clave (Lenin, 1946: 61; Engels, 1948: 146); en la filosofía moderna lo encontramos en las antinomias de Kant y luego en el tratamiento de los "posiblesimposibles" de Derrida, en el don, la hospitalidad, el perdón y el duelo (Guille, 2015). En esta línea pueden añadirse la nuda vida en la soberanía (Agamben, 1998); la nada como algo que no existe y lo virtual como organizador material de la postmodernidad.
} 
Observando el proceso político tejido en torno al puente desde el prisma conceptual de la aporía, la arena política donde se pone en juego lo metropolitano se revela como efecto de Estado y que el papel material de la infraestructura tiene que ver con legitimar la producción (social, jurídica, consuetudinaria, cotidiana, idiosincrásica) de totalidades sociales significativas donde actores concretos buscan inscribir y crear obras. La aporía abre, en lugar de cerrar, la pregunta sobre la relación entre la obra y la escala urbana gracias a reconocer la dinámica social por la cual se manifiesta simultáneamente la presencia y la ausencia del poder del Estado.

Así enfocado nuestro caso, evitamos caer en el metodologismo de tomar la discusión metropolitana del puente como si fuera una contradicción, un problema de los actores. ${ }^{8}$ Porque la ambigüedad del proyecto (la conectividad como algo predecible e impredecible que merece ser promovido y al mismo tiempo controlado) radica menos en los desacuerdos respecto de cómo planificar el ordenamiento territorial que en las controversias que giran en torno a precisiones de lo urbano qua metropolitano. $\mathrm{Su}$ eficacia reside en y a través de los procesos políticos donde actores concretos despliegan la capacidad de transformar un puente en una metropolización. Un puente entre dos ciudades y la planificación de una metrópolis son los polos móviles del mismo movimiento que 'conecta' las fuerzas políticas del presente. Si la conectividad y la metropolización aparecen separadamente como efectos materiales de la imaginación de escalas urbanas, es justamente porque los actores (las personas y las instituciones, incluyendo universidades, empresas y gobiernos) son capaces de transitarlos y conectarlos. En suma, el puente no es tanto la obra del viaducto entre dos ciudades, sino la metropolización como un proyecto político.

\footnotetext{
${ }^{8}$ Vale la pena recordar que los antropólogos solemos acordar en que el "deber ser" de las normas siempre está desajustado de los "procesos reales" (Malinowski, 1986), pero sucumbimos al pensamiento normativo al tomar las ambigüedades como contradicciones y/o esforzarnos por resolverlas.
} 


\section{Conclusiones}

Para concluir me gustaría volver a un punto poco explicitado en el comienzo de este trabajo acerca del viaje a lo local ante todo como un movimiento analítico. Recurriré a un pequeño fragmento de mi trabajo de campo en la ciudad de Paraná.

"Mucho relato y poca obra", me señaló con desconfianza una ingeniera entrerriana cuando le pregunté por el puente Santa Fe-Paraná. Sin embargo, luego de charlar en su oficina y una fugaz visita guiada por las fotos y planos relacionados con la obra que colgaban en una de las paredes al fondo del edificio, terminó ofreciéndome una publicación elaborada por el Colegio de Profesionales de la ingeniería civil, en el cual presentan “propuestas para el desarrollo de la provincia y de la región”. Este número especial estaba dedicado al "puente Paraná-Santa Fe" (nótese la ciudad que encabeza el nombre), a su "necesidad" (por ser una región aislada y por agotamiento progresivo del Túnel Subfluvial debido al aumento sostenido del tráfico y a la posibilidad de un colapso por obra de la naturaleza), y a su "factibilidad" (técnica y económica proponiendo al ente Interprovincial del Túnel Subfluvial a cargo a través de créditos del BID y Banco Mundial). Entre los argumentos, deslizaban también un curioso análisis del artículo 124 de la Constitución Nacional de 1994 (el mismo que habilitó la creación de la Región Centro), de que las provincias "recuperaron" el dominio originario de los recursos naturales en su territorio y podrían autorizar la construcción de un puente entre ambas. Pero el eje de la publicación son las "propuestas": un viaducto, proyecto de las "entidades intermedias", que "será propiedad de la sociedad cuando ella la impulse", e "incrementará las relaciones comerciales a partir de definir a la región como una metrópolis".

Este fascículo - sin fechas, páginas, ni autores - condensa la poderosa y lábil existencia de la aporía como organizadora del trabajo de campo y del estudio antropológico de los procesos políticos. Este pasaje en la institución colegiada a los especialistas de la infraestructura, no es externo al evento antes discutido y analizado sino que le pertenece de una manera indisociable al proceso político tejido en torno al puente Santa Fe-Paraná. De hecho, lo mismo ocurre con lo casual e inesperado de ese trabajo de campo y de los caminos que me llevaron al Paraninfo de la UNL. El traspié etnográfico de la ausencia devenida en presencia de la intendente de Paraná, el pintoresco viaje en taxi la noche anterior, la madrugada, el ruidoso viaje subacuático por 
el túnel; todo hizo sentido con lo que vendría después en el trabajo de campo: las entrevistas a diferentes funcionarios del sector público y del privado, reuniones con ambientalistas, esperas en los pasillos del edificio de Vialidad buscando documentación, y hasta la invitación que me hicieron los empresarios de la Región Centro a la X Jornada de la Industria y el Comercio Exterior organizada por la Unión Industrial de Entre Ríos. Por razones de economía expositiva no puedo detenerme (como quisiera) en los detalles de esos espacios de la etnografía, pero quisiera destacar que su sentido de totalidad no resulta de la sumatoria de partes, sino de una operación de transformación analítica. Al dejar de pensar en términos de procesos políticos relevables, como por ejemplo, el estado de situación de un proyecto de obra, y pasar a cuestionar esa pregunta inicial, irrumpió lo que era relevante para los actores. Eso relevante es una totalidad ambigua, que reúne experiencias de tiempos y espacios contradictorios. Reconocer sus relaciones como tensión entre la política y lo político (Slater, 1998) permite dar cuenta de la política como un proceso vivo (Fernández A. et al., 2017) que, como la obra del puente, es un proyecto de definición y establecimiento de límites móviles -más sociales y políticos, que jurídicos y económicos- entre lo metropolitano y lo no metropolitano.

El ingeniero que hace cálculos para construir un pilote de hormigón sobre el lecho de un río, un funcionario que gestiona un crédito internacional, la consultora que evalúa el costo medioambiental, un legislador que sanciona una ley para evitar accidentes, los padres que tramitan el boleto estudiantil de sus hijos, ecologistas que cortan un camino en forma de denuncia, el automovilista que toca bocina para no pagar un peaje que se demora; son prácticas y experiencias del espacio diferentes pero siendo sus relaciones lo que permiten pensarlas como tales. El carácter sistemático de esta relación es, no obstante, una dimensión axiológica más que real. La producción de escalas urbanas como un proyecto político asociado a la infraestructura es un pivote de la producción de estructuras desiguales de imaginación. Rutas, caminos, puentes son celebrados pese a fallar en cumplir la promesa de conectividad, son anhelados aun cuando aseguran exclusiones violentas de los órdenes sociales establecidos, y son temidos aun cuando demuestran seguridad. Al igual que conectividad y aislamiento son evaluaciones sobre el territorio y no características del mismo, un puente puede significar que la nación (un o una presidente) llegue en helicóptero a un pueblo que se sentía aislado. Pensar en términos de aporía en lugar de contradicción de lo urbano metropolitano conforma, quizás, una alternativa a la definición de tipologías de espacios 
y actores por cuanto permite una manera renovada de observar las dos formas más usuales de pensar las relaciones entre Estado e infraestructura pública (en sus efectos materiales y como topología del poder). Seguir explorando los fundamentos cotidianos y excepciones por los cuales los caminos pueden forjar imaginarios urbanos es una manera de renovar el estudio de lo urbano como producción de contexto social de coordenadas humanas, simbólicas y materiales, de relación entre naturaleza y cultura, y definitivamente, de proyectos políticos que no siempre, o casi nunca, se cristalizan institucional, material o patrimonialmente.

\section{Referencias}

AGAMBEN, Giorgio. Homo sacer. El poder soberano y la nuda vida. Valencia: PreTextos, 1998.

AGNEW, John. Geopolítica: una re-visión de la política mundial. Madrid: Trama, 2005 APPADURAI, Arjun. La modernidad desbordada. Buenos Aires: Trilce - FCE, 2001.

ABRAM, Simone; WESZKALNYS, Gisa (eds.). Elusive Promises: Planning in the Contemporary World. Aldershot: Ashgate, 2013

ABRAM, Simone. The time it takes: temporalities of planning. Journal of the Royal Anthropological Institute, 20, S1, 2014, p. 129-147. DOI: 10.1111/1467-9655.12097

BARTH, Fredrik. O guru, o iniciador e outras variações antropológicas. Rio de Janeiro: Contracapa, 2000.

BAUMAN, Zigmut. Liquid times: Living in an age of uncertainty. Cambridge: Polity Press, 2007.

BEAR, Laura (Ed.) Doubt, conflict and mediation: the anthropology of modern time. Journal of the Royal Anthropological Institute, 20 (S1), 2014, p. 3-30, DOI: 10.1111/1467-9655.12091

BORJA, Joao; CASTELLS, Manuel. Local y Global. La gestión de las ciudades en la era de la información. Madrid: Taurus, 1997.

BOURDIEU, Pierre. Acts of Resistance: Against the New Myths of Our Time. Oxford: Polity Press, 1998.

CARMONA, Rodrigo. El desafío de gobernar ciudades en Argentina. Alcances y perspectivas en materia de organización política y administrativa. Revista de Direito da Cidade, 7, 1, 2015, p. 206-225.

CARRITHERS, Michael. Anthropology as Irony and Philosophy, or the Knots in Simple Ethnographic Projects. Hau: Journal of Ethnographic Theory, 4, 3, 2014, p. 117-142.

CAVALLAR, Jonathan. Las Paradojas del Movimiento de Zenón de Elea y el Testimonio Platónico. Aporía, Revista Internacional de Investigaciones Filosóficas, 2 2011, p. 77-93.

CECEÑA, Ana,. AGUILAR, Paula; MOTTO, Carlos. Territorialidad de la dominación. Buenos Aires: Observatorio Latinoamericano de Geopolítica, 2007.

CERVANTES SAAVEDRA, Miguel de. El ingenioso hidalgo Don Quijote de la Mancha. Madrid: Calleja editorial, 1910 [1605] 
DALAKOGLOU, Dimitris. Infrastructural gap Commons, state and anthropology. CITY, 20, 6, 2016, p. 822-831

DALAKOGLOU, Dimitris; HARVEY, Penny. Roads and Anthropology: Ethnographic Perspectives on Space, Time and (Im)Mobility. Mobilities, 7, 4, 2012, p. 459-465.

DAS, Vena; POOLE, Deborah. El Estado y sus márgenes. Cuadernos de Antropología Social, 27, 2008, p.19-52.

DEVONS, Ely; GLUCKMAN, Max (Eds.). Closed systems and open minds: the limits of naivety in social anthropology. Edinburgh: Oliver \& Boyd, 1964.

ELYACHAR, Julia. Next Practices: Knowledge, Infrastructure, and Public Goods at the Bottom of the Pyramid. Public Culture, 24, 66, 2012, p. 109-129; doi:10.1215/08992363-1443583

ENGELS, Friedrich. Anti-Dühring, Montevideo: Ediciones Pueblos Unidos, 1948. ERIKSEN, Thomas. Globalization: The Key Concepts. Londres: Bloomsbury, 2014 ESCOLAR, Marcelo; BADÍA, Gustavo; FREDERIC, Sabina (Eds.). Federalismo y descentralización en grandes ciudades: Buenos Aires en perspectiva comparada. Buenos Aires, Argentina: Prometeo, 2004.

FERNÁNDEZ ÁLVAREZ, María Inés; GAZTAÑAGA, Julieta; QUIRÓS, Julieta. La política como proceso vivo: diálogos etnográficos y un experimento de encuentro conceptual. Revista Mexicana de Ciencias Políticas y Sociales, [S.1.], 62, 231, 2017, Disponible en: <http://www.revistas.unam.mx/index.php/rmcpys/article/view/54749>. Fecha de acceso: 20 sep. 2017

GAZTAÑAGA, Julieta. El trabajo político y sus obras. Una etnografía de tres procesos políticos en la Argentina contemporánea. Buenos Aires: GIAPER y Antropofagia, 2010a.

GAZTAÑAGA, Julieta, El puente Victoria-Rosario y el corredor bioceánico central. In: ROATO, Ana (comp.) Construyendo integración al interior del MERCOSUR. Buenos Aires: GIAPER y Antropofagia, p. 127-144, $2010 \mathrm{~b}$.

GAZTAÑAGA, Julieta, Integraciones subnacionales desde la antropología social. Saarbrücken: EAE, 2012.

GAZTAÑAGA, Julieta. Una perspectiva antropológica sobre el federalismo y el conflicto agropecuario en la Región Centro. Revista Interdisciplinaria de Estudios Sociales, 6, 2013, p. 11-35.

GAZTAÑAGA, Julieta. "La política del valor y la política del significado, tendiendo puentes", Antípoda, Revista de Antropología y Arqueología, 24, 2016, p: 111-130. http://dx.doi.org/10.7440/antipoda24.2016.07. ISSN: 2011-4273.

GAZTAÑAGA, Julieta; PIÑEIRO Julia; FERRERO, Laura. Afectos y efectos de Estado: procesos políticos en torno de la creación de infraestructura, planificación urbana y turistificación. Revista Estudios Sociales del Estado, 2, 2016, p. 125-153.

GIGLIA, Angela, Entre el bien común y la ciudad insular: la renovación urbana de la ciudad de México, Alteridades, 23, 46, 2013, p. 27-38.

GLUCKMAN, Max. Analysis of a social situation in Modern Zululand. RhodesLivingstone Paper No 28, Manchester: Manchester University Press, 1958.

GODELIER, Maurice; BLOCH, Maurice; CLAESSEN, , H. J; GILMORE, D. D; PISUNYER, O; TAGÁNYI, Z. Infrastructures, Societies, and History [and Comments]. Current Anthropology 19, 1978, p. 763-771.

GRAEBER, David Toward an Anthropological Theory of Value: The False Coin of Our Own Dreams. Nueva York: Palgrave, 2001.

GRAEBER, David. The Anthropology of Globalization (with Notes on Neomedievalism, and the End of the Chinese Model of the State). American Anthropologist, 104, 4, 2002, p. 1222-1227. 
GRAHAM, Stephen; MARVIN, Simon. Splintering Urbanism: Networked Infrastructures, Technological Mobilities and the Urban Condition. London -New York: Routledge, 2001.

GRAVANO, Ariel. Tres hipótesis sobre la relación entre sistema urbano e imaginarios de ciudades medias. In GRAVANO, Ariel; SILVA, Ana; BOGGI, Silvia. Ciudades vividas. Sistemas e imaginarios de ciudades medias bonaerenses. Buenos Aires: Café de las ciudades; p. 69-90, 2016.

GRAVANO, Ariel (comp.). Imaginarios de la ciudad media: emblemas, fragmentaciones y otredades urbanas. Estudios de Antropología Urbana. Tandil: REUN, 2005.

GREEN, Sarah; LAVIOLETTE, Patrick. Editorial. Social Anthropology, 25, 2017, p. 3 4. doi: 10.1111/1469-8676.12391.

GUILLE, Gustavo P. Las aporías de la hospitalidad en el pensamiento de Jacques Derrida, Eikasia. Revista de Filosofía, 64, 2015, p. 263-276

GUPTA, Akhil. Postcolonial Developments: Agriculture in the Making of Modern India. Durham: Duke University Press,1998.

GUYER, Jane. Prophecy and the near future: thoughts on macroeconomic, evangelical, and punctuated time. American Ethnologist, 34, 3, 2007, p. 409-421.

HANNERZ, Ulf. Transnational connections: Culture, people, places. New York: Routledge, 1996.

HARRIS, Marvin. Cultural Materialism. Walnut Creek: Altamira Press, 1968.

HARVEY David. La condición de la posmodernidad: Investigación sobre los orígenes del cambio cultural Buenos Aires: Amorrortu, 1998.

HARVEY, David. El “nuevo" imperialismo : acumulación por desposesión. Buenos Aires: CLACSO, 2005.

HARVEY, Penelop. La materialidad de los efectos de Estado. In KROHN, Christian; NUSTAD, Knut (Eds.) State Formations. London: Pluto Press, p.142-167, 2005.

JENSEN, Ole. Staging Mobilities. London: Routledge, 2013

KAUFMANN, V Vincent; BERGMAN, Manfred M.; JOYE Dominique. Motility: Mobility as Capital. International Journal of Urban and Regional Research, 28, 2004, p. 745-756.

KROTZ, Esteban. Alteridad y pregunta antropológica. In: BOIVIN M.; A. ROSATO y V. ARRIBAS, Constructores de otredad. Buenos Aires: Antropofagia, 2007 [1994].

LANDAU, Matías. La ciudad y sus partes: una historia de la institucionalidad local en la Ciudad de Buenos Aires. EURE, 40, 119, 2014, p. 151-171.

LE BART, Christian; LEFEBVRE, Remi. La proximité en politique. Usages, rhétoriques, pratiques. Rennes: Presses Universitaires de Rennes, 2005.

LEFEBVRE, Henri. The production of space. Oxford: Blackwell Publishing, 1991 [1974].

LLOP, Josep; USON, Ezequiel (Eds.). Ciudades Intermedias. Dimensiones y definiciones. Lleida: Milenio, 2014.

LOIS, María. Estructuración y espacio: la perspectiva de Lugar. Geopolítica(s). Revista de estudios sobre espacio y poder, 1, 2, 2010, p. 207-231.

MAINS, Daniel. Blackouts and Progress: Privatization, Infrastructure, and a Developmentalist State in Jimma, Ethiopia. Cultural Anthropology, 27, 1, 2012, p. 3-27. MALINOWSKI, Bronislaw. Crimen y costumbre en la sociedad salvaje. Barcelona: Planeta-De Agostini, 1986.

MASSEY, Doreen. For space. London: Sage, 2005.

MINTZ, Sidney. Sweetness and power: the place of sugar in modern history. New York: Viking -Penguin, 1985 
MITCHELL, Timothy. Everyday Metaphors of Power. Theory and Society, 19, 5, 1990, p. 545-577.

OLIVO, Julio. La iniciativa IIRSA y el ordenamiento del territorio continental. Lima: Forum Solidaridad, 2008.

PEREZ NEGRETE, Margarita. Santa Fe: ciudad, espacio y globalización. México: UIA, 2010

ROSATO, Ana (comp.). Construyendo integración al interior del Mercosur: la integración entrerriano-riograndense (1992-2001). Buenos Aires: AntropofagiaGiaper, 2010.

RIBEIRO, Gustavo. Empresas Transnacionais. Um grande projeto por dentro. Sao Paulo: Marco Zero y Anpocs, 1991.

ROSENTAL, Mark; IUDIN, Pavel. Diccionario filosófico marxista. Montevideo: Ediciones Pueblos Unidos, 1946.

SALAZAR, Noel. Towards an anthropology of cultural mobilities. Crossings: Journal of Migration and Culture, 1, 2010, p. 53-68.

SALAZAR, Noel; JAYARAM, Kiran (Eds.) Keywords of mobility, Critical Engagements. New York: Berghahn Books, 2016.

SASSES, Saskia. The Global City. New Jersey: Princeton University Press, 1999

SLATER, David. Rethinking the Spatialities of Social Movements. In: ALVAREZ, SONIA; DAGNINO, Evelyn; ESCOBAR, Arturo (Eds.) Cultures of Politics, Politics of Culture. Boulder: Westview, p. 380-401, 1998.

STAR, Susan The Ethnography of Infrastructure. American Behavioral Scientist, 43(3): 1999, p. 377-391.

TROUILLOT, Michael. Transformaciones globales: la antropología y el mundo moderno. Cauca-Bogotá: Universidad del Cauca U. de los Andes, 2011.

TSING, Anna. The Global Situation. Cultural Anthropology, 15, 3, 2000, p. 327-360.

TSING, Anna. Friction: An ethnography of global connection. Princeton: Princeton University Press, 2005.

TURNER, Bryan. The enclave society: Towards a sociology of immobility. European Journal of Social Theory, 10,2, 2007, p. 287-303.

URRIZA, Guillermina; GARRIZ, Eduardo. ¿Expansión urbana o desarrollo compacto? Estado de situación en una ciudad intermedia: Bahía Blanca, Argentina. Revista Universitaria de Geografía, 23, 2, 2014, p. 97-123.

URRY, John. Mobilities. Cambridge: Polity Press, 2007.

WOLF, Eric. Europa y la gente sin historia. Buenos Aires: Fondo de Cultura Económica, 1993.

ZUNINO S., Dhan. El Subte como artefacto cultural (Buenos Aires, 1886-1944). Revista Transporte y Territorio, 9, 2013, p. 173-200.

Recebido em: 21/09/2017. Aprovado em: 15/11/2017. 